\title{
ANGULAR MEASUREMENTS OF HTS CRITICAL CURRENT FOR HIGH FIELD SOLENOIDS
}

\author{
D. Turrioni ${ }^{1}$, E. Barzi ${ }^{1}$, M. Lamm ${ }^{1}$, V. Lombardo ${ }^{1}$, C. Thieme ${ }^{2}$, and \\ A. V. Zlobin ${ }^{1}$, \\ ${ }^{1}$ Fermi National Accelerator Laboratory \\ Batavia, Illinois, 60510, USA \\ ${ }^{2}$ American Superconductor (AMSC) \\ Westborough, MA, 01581, USA
}

\begin{abstract}
An experiment is in the works at Fermilab to confirm that ionization cooling is an efficient way to shrink the size of a muon beam. This would pave the way for Muon Collider machines, which however require in their last stages of acceleration very high field solenoids. The use of high temperature superconducting materials (HTS) is being considered for these magnets using Helium or higher temperature refrigeration. A sample holder was designed to perform critical current $\left(\mathrm{I}_{\mathrm{c}}\right)$ measurements of HTS conductors under externally applied magnetic fields varying from zero to 90 degree with respect to the c-axis. This was performed in an ample range of temperatures and magnetic field values. A description of the test setup and results for $(\mathrm{Bi}, \mathrm{Pb})_{2} \mathrm{Sr}_{2} \mathrm{Ca}_{2} \mathrm{Cu}_{3} \mathrm{O}_{x}$ (BSCCO-2223) tapes, and Second Generation HTS in the form of 348 superconductor are presented.
\end{abstract}

KEYWORDS: High temperature superconductor, BSCCO, DC measurement.

\section{INTRODUCTION}

First Generation $(1 \mathrm{G})$ multi-filamentary HTS are composites of silver or silver alloy matrix and BSCCO [1]. Second Generation (2G) HTS conductor is based on a thin film approach. Transverse cross sections of a $2 \mathrm{G} 344$ coated conductor and a $1 \mathrm{G}$ Hermetic BSCCO-2223 tape are shown in Figure 1. 2G HTS wire is now seen as the major candidate for a lower cost HTS wire in the near future and an effective replacement for 1G HTS wire. 


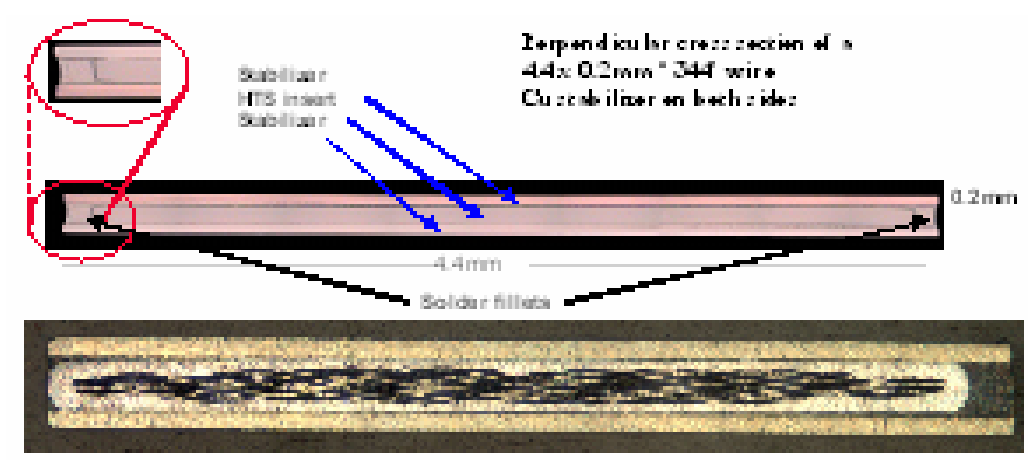

FIGURE 1. Transverse cross section of a $2 \mathrm{G} 344$ coated conductor showing a YBCO layer $1 \mu \mathrm{m}$ thick (top). Transverse cross section of a 1G Hermetic BSCCO-2223 tape showing 55 filaments of BSCCO-2223 embedded in a silver alloy matrix and $37 \mu \mathrm{m}$ strips of stainless steel on top and bottom and solder fillets at the sides (bottom).

Both conductor types offer comparable electrical properties at lower temperatures. $2 \mathrm{G}$ becomes progressively superior to $1 \mathrm{G}$ when temperatures approach $77 \mathrm{~K} .2 \mathrm{G}$ has excellent mechanical properties, and allows a react-and-wind technique for magnet construction.

The active component is the $\mathrm{YBCO}\left(\mathrm{YBa}_{2} \mathrm{Cu}_{3} \mathrm{O}_{7}\right)$ or $(\mathrm{RE}) \mathrm{BCO}$ layer, which is only around $1 \mu \mathrm{m}$ thick. Despite the fact that only one such layer is present in a single conductor, the engineering critical currents are comparable to those of $1 \mathrm{G}$ wire. The corresponding critical current density in the YBCO layer is therefore very high $\left(>20 \mathrm{kA} / \mathrm{mm}^{2}\right.$ at $77 \mathrm{~K}$, selffield), but this high $\mathrm{J}_{\mathrm{c}}$ requires well-aligned $\mathrm{YBCO}$ grains. Typically, the YBCO grain boundary mis-orientation angle is below $3-4^{\circ}$, and the templates for growing these near-single crystal-like YBCO films are therefore well-textured. American Superconductor (AMSC) uses a bi-axially textured substrate approach onto which a thin epitaxial oxide buffer layer is deposited (RABiTS ${ }^{\mathrm{TM}}$ ) [2,3]. The epitaxial superconducting YBCO layer is grown using a low-cost, solution-based Metal Organic Deposition (MOD) process [4]. The coating processes allow a $40 \mathrm{~mm}$ or wider process width. After YBCO reaction and Ag coating the conductor is slit to near-final conductor width, typically $4 \mathrm{~mm}[5,6]$. This slit "insert" conductor is then laminated on both sides to a slightly wider $(4.4 \mathrm{~mm})$ foil, which can consist of different materials. Copper laminates are used for coil and cable applications; stainless laminates are used for fault current limiters. This 3-ply geometry is now sold by AMSC as " 344 " superconductors. The " 3 " indicates the 3-ply geometry and 44 the $4.4 \mathrm{~mm}$ width. The laminate provides mechanical, electrical and thermal stability and facilitates a robust winding process for coil applications. AMSC also developed a slightly wider conductor, the so-called 348 superconductor ( $4.8 \mathrm{~mm}$ wide). This wider superconductor was used for this work.

BSCCO-2223 and 2G HTS are typically produced in the form of tapes, which are anisotropic and exhibit the highest critical current when the magnetic field is applied parallel to the tape face $\left(\mathrm{B}_{\mathrm{PAR}}\right)$ and the lowest one when the field is perpendicular $\left(\mathrm{B}_{\mathrm{PERP}}\right)$. Figure 2 shows the geometrical configuration of a tape and relative directions of magnetic field.

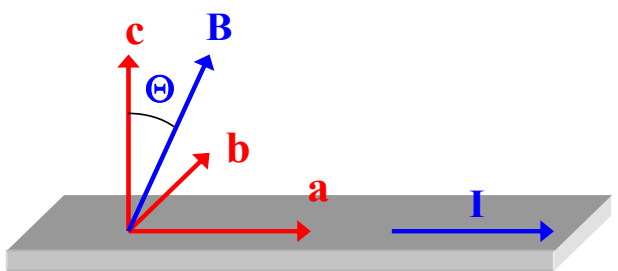

FIGURE 2. HTS superconductor with current direction and relative direction of magnetic field B. B is always perpendicular to the current direction. 

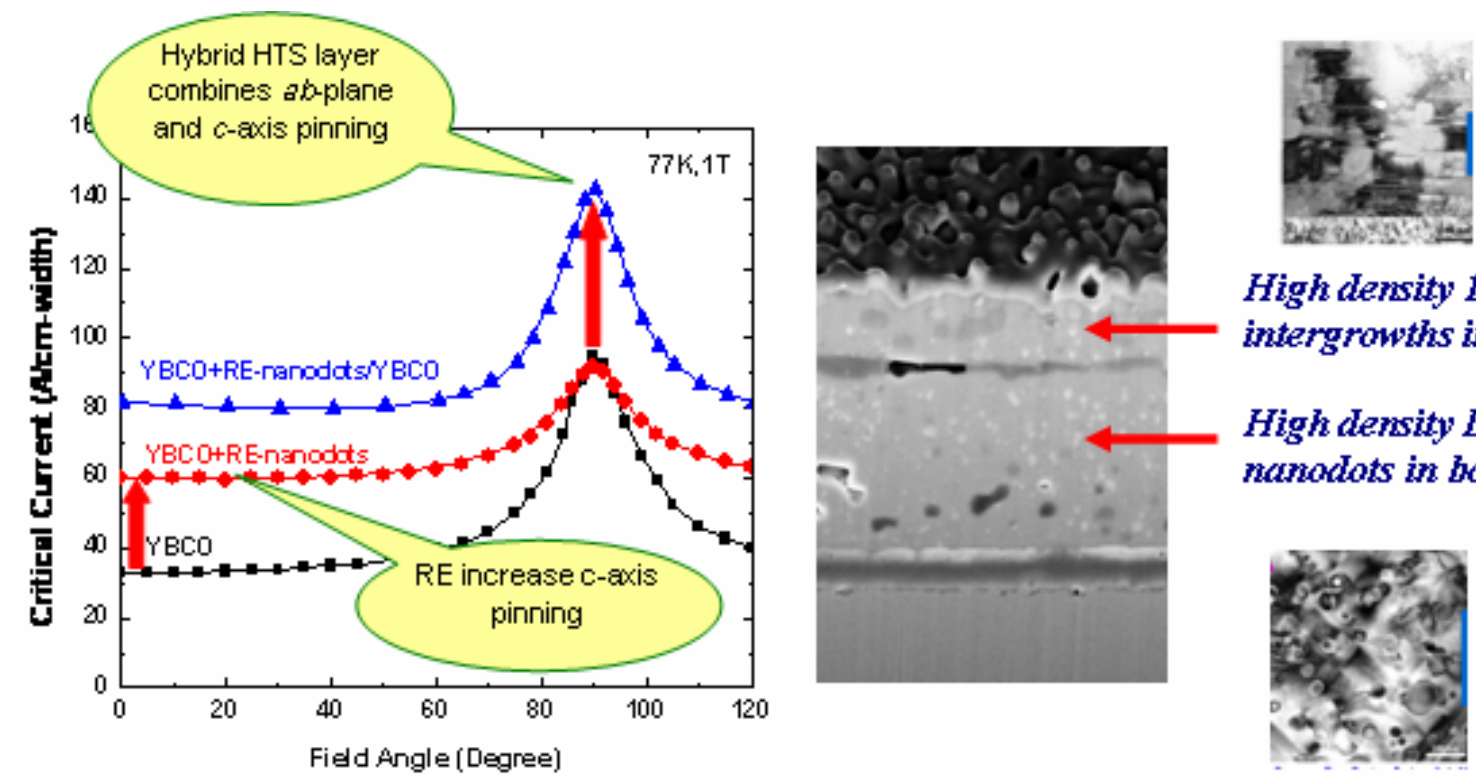

High density 124

intergrowths in top

High density $D y$ nanodots in bottom

FIGURE 3. Field-angle dependence of $\mathrm{I}_{\mathrm{c}}(77 \mathrm{~K}, 1 \mathrm{~T})$ in a conductor with a $1.4 \mu \mathrm{m}$ thick hybrid layer (left). At right, top layer is undoped YBCO with planar defects, bottom layer is doped with RE oxide for c-axis pinning.

Flux pinning in YBCO can be strongly influenced by additions of rare earth oxides, in particular when they segregate as small particles ("nanodots") which tend to enhance pinning for field orientations perpendicular to the YBCO film plane [6,7]. Stacking faults are very effective in enhancing pinning for field orientations parallel to the film plane. To use the advantages of both pinning mechanisms a Double Layer Hybrid was developed. An example is shown in Figure 3 at right [6], where nanodots (see bottom TEM image) enhance the perpendicular-field $I_{c}$ values and the planar 124 stacking faults (top TEM image) maintain effective ab-plane pinning. Figure 3 (left) also shows that at $77 \mathrm{~K}, 1 \mathrm{~T}$ the performance of this new conductor using this hybrid YBCO layer, approximately $1.4 \mu \mathrm{m}$ thick, is enhanced over the entire angular range.

Earlier BSCCO tapes have been tested at various temperatures in both field directions [8]. Angular measurements on PLD and MOD YBCO have mainly focused on higher temperatures [9]. In this study we were interested in the capabilities of both superconductors for potential high field solenoids, suitable for future Muon Collider systems, and for this application, the choice in temperature ranged from $1.8 \mathrm{~K}$ to $33 \mathrm{~K}$, at magnetic fields up to $15 \mathrm{~T}$. We also measured the magnetic field dependence as a function of magnetic field angle $\Theta$.

\section{EXPERIMENTAL SETUP}

\section{Samples Description}

A BSCCO-2223 Hermetic tape and a 2G 348 Coated conductor produced by AMSC were tested. Samples specifications are given in Table 1. 
TABLE 1. HTS Specifications (2G HTS performance for this study slightly higher than quoted 110A)

Min $\mathrm{I}_{\mathrm{c}}(77 \mathrm{~K}$, self-field, $1 \mu \mathrm{V} / \mathrm{cm})$

Average thickness $\mathrm{t}_{\mathrm{T}}$

Average width $\mathrm{w}_{\mathrm{T}}$

Laminate

Laminate thickness

YBCO layer thickness

Min. critical bend diameter

Max. rated tensile strain $\left(95 \% \mathrm{I}_{\mathrm{c}}\right.$ retention $)$

Hermetic BSCCO-2223 tape

$115 \mathrm{~A}$

$0.31 \mathrm{~mm}$

$4.8 \mathrm{~mm}$

stainless

$2 \times 0.037 \mathrm{~mm}$

$50 \mathrm{~mm}$

$0.3 \%$
348 Superconductor

$110 \mathrm{~A}$

$0.2 \mathrm{~mm}$

$4.8 \mathrm{~mm}$

copper

$2 \times 0.050 \mathrm{~mm}$

$1.4 \mu \mathrm{m}$

$50 \mathrm{~mm}$ $0.3 \%$

\section{Sample Holders}

Samples were $38 \mathrm{~mm}$ long. Figure 4 shows the sample holder that was designed and used to change the direction of the c-axis of the tape with respect to the external magnetic field. The sample, supported in its middle part by G-10, was soldered within a groove on two $\mathrm{Cu}$ half cylinders (Figure 4, left). A splice length of $12 \mathrm{~mm}$ was used on each side of the sample to control contact resistance and heating power. The sample holder was placed at the desired angle within cylindrical holes in the probe $\mathrm{Cu}$ lugs (Figure 4, center). To provide electrical contact the lugs were then tightened using stainless steel screws. Current transfer length requirements determined the distance between the voltage taps, which was of $10 \mathrm{~mm}$ (Figure 4 , right).

\section{Measurement Procedure}

Critical current measurements were performed at Fermilab Superconductor R\&D lab. Measurements were obtained at the various temperatures in a Variable Temperature Insert (VTI) with an inner diameter of $49 \mathrm{~mm}$, within a 15/17 T magneto-cryostat. The current was provided to the sample using 2000 A current leads. The angle $\Theta$ was changed in steps of $11.25^{\circ}$ and $22.5^{\circ}$. First, critical current measurements were performed in liquid nitrogen $(77 \mathrm{~K})$ in self-field. Next, voltage-current (VI) characteristics were measured in He (liquid or vapor) at a magnetic field between 0 and $15 \mathrm{~T}$. The critical current $I_{c}$ was determined using the $1 \mu \mathrm{V} / \mathrm{cm}$ criterion, with the usual measurement uncertainties [10]. Critical currents have not been corrected for self field effects which can be substantial at low fields.
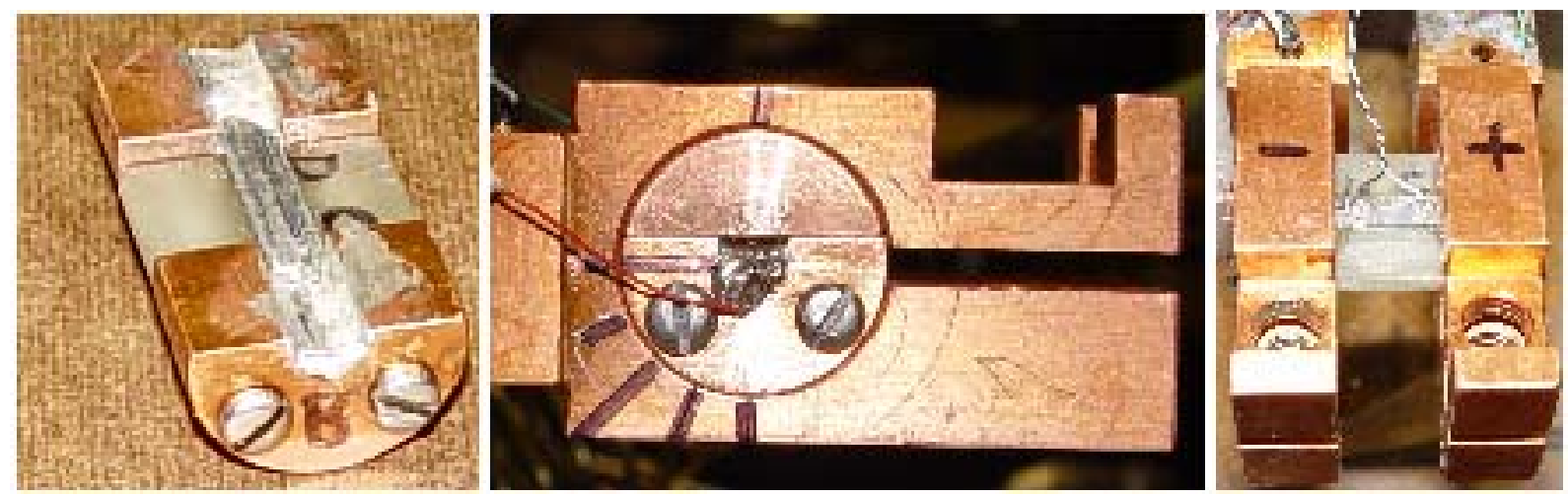

FIGURE 4. Sample holder (left), sample holder within the probe copper lugs (center), and instrumented sample (right). 


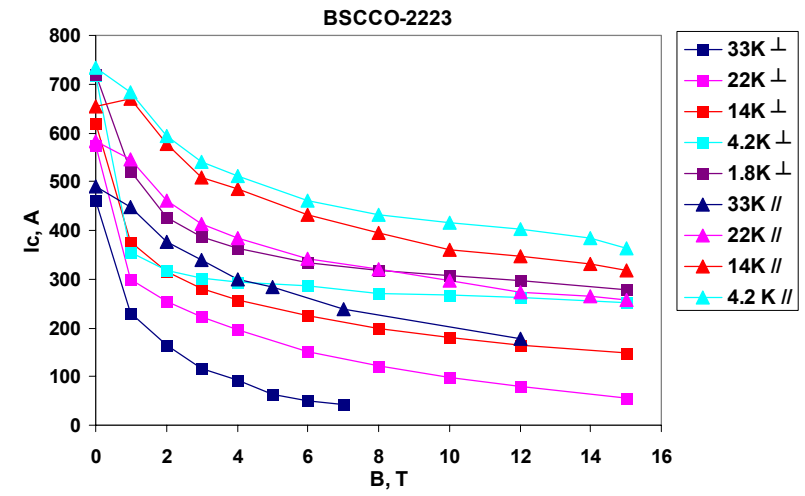

FIGURE 5. $\mathrm{I}_{\mathrm{c}}(\mathrm{B}, \mathrm{T})$ of the $\mathrm{Bi}-2223$ hermetic wire in parallel and perpendicular fields, $1.8-33 \mathrm{~K}$.

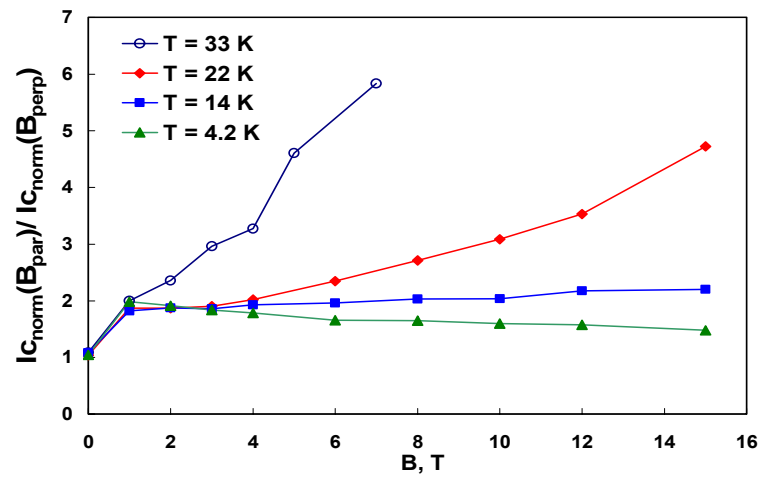

FIGURE 6. Ratio of normalized $\mathrm{I}_{\mathrm{c}}$ in parallel and perpendicular fields, 4.2-33 K, for the Bi-2223.

\section{RESULTS AND DISCUSSION}

\section{BSCCO-2223 Hermetic Wire}

Figure 5 shows $I_{c}$ results as a function of magnetic field for the BSCCO-2223 tape, in the parallel and transverse field configurations, from $1.8 \mathrm{~K}$ to $33 \mathrm{~K}$. The $\mathrm{I}_{\mathrm{c}}$ test results in nitrogen at $77 \mathrm{~K}$ were $122 \pm 1 \mathrm{~A}$. The $\mathrm{I}_{\mathrm{c}}$ performance at $1.8 \mathrm{~K}$ was more than $10 \%$ better up to $15 \mathrm{~T}$. It is also worth noting that these hermetic tapes were able to perform without any degradation after several thermal cycles.

To gauge field and temperature dependence of the anisotropy, the ratio of $I_{c}$, normalized to $\mathrm{I}_{\mathrm{c}}(77 \mathrm{~K}, 0 \mathrm{~T})$, in parallel field to that in transverse field as a function of applied magnetic field at the various temperatures is plotted in Figure 6. One can see that this ratio depends on both field and temperature. The field dependence is consistent with a linear one, where the slope value increases with temperature.

Figures 7 and 8 show the angular dependence. The $I_{c}$ normalized to $I_{c}(77 \mathrm{~K}, 0 \mathrm{~T})$ as a function of the field angle at various magnetic fields is plotted at $4.2 \mathrm{~K}$ and $33 \mathrm{~K}$. The data taken at $0 \mathrm{~T}$ field are shown as representative of the measurement uncertainty. Most of the $\mathrm{I}_{\mathrm{c}}$ reduction occurs between 90 and 45 degree.

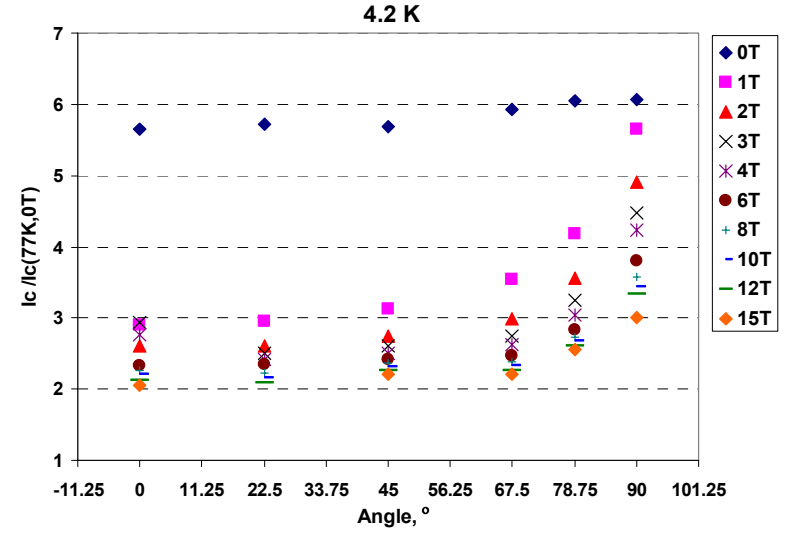

FIGURE 7. Normalized $\mathrm{I}_{\mathrm{c}}(4.2 \mathrm{~K})$ of the $\mathrm{Bi}-2223$

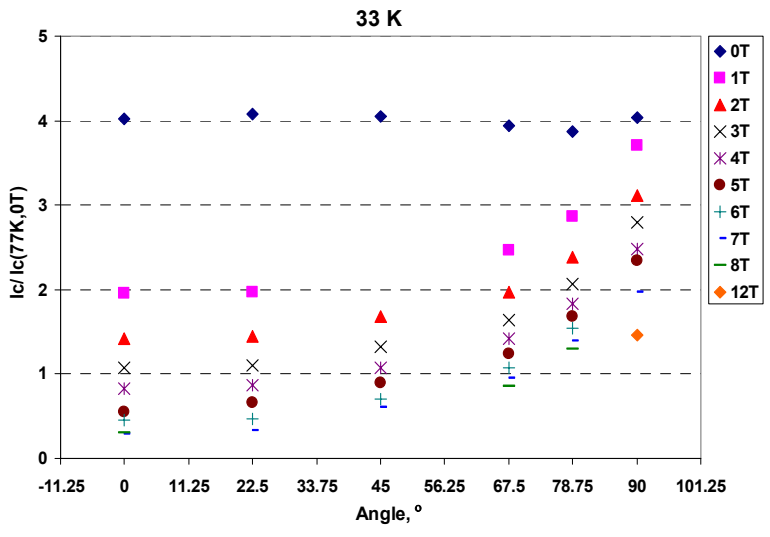

FIGURE 8. Normalized $\mathrm{I}_{\mathrm{c}}(33 \mathrm{~K})$ of the $\mathrm{Bi}-2223$ 
hermetic conductor versus $\mathrm{B}$ and $\Theta$.

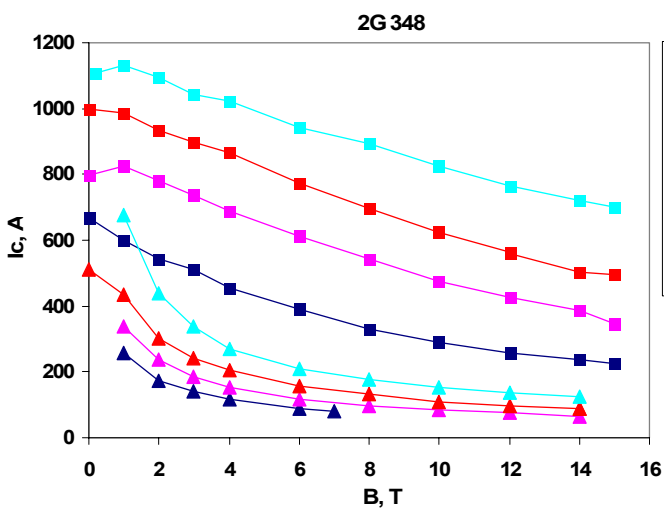

FIGURE 9. $\mathrm{I}_{\mathrm{c}}(\mathrm{B}, \mathrm{T})$ of the hybrid $2 \mathrm{G} 348$ in parallel and perpendicular fields, 4.2-33 K. hermetic conductor versus B and $\Theta$.

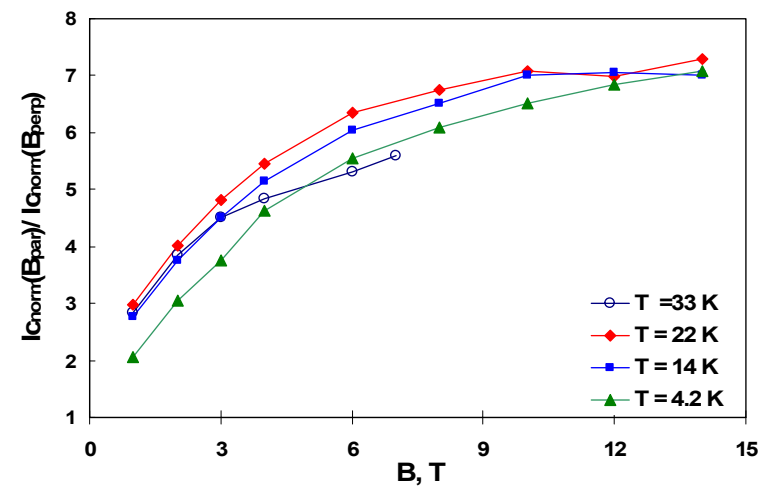

FIGURE 10. Ratio of normalized $I_{c}$ in parallel and perpendicular fields, $4.2-33 \mathrm{~K}$, for the $2 \mathrm{G} 348$.

\section{G 348 Coated Conductor}

Figure 9 shows $I_{c}$ results as a function of magnetic field for the $2 \mathrm{G} 348$ conductor, in the parallel and transverse field configurations, from $4.2 \mathrm{~K}$ to $33 \mathrm{~K}$. The performance at self-field and $77 \mathrm{~K}$ was $127 \mathrm{~A}$ for the sample tested in parallel configuration and $153 \mathrm{~A}$ for that used in the transverse configuration. One can see that the $\mathrm{I}_{\mathrm{c}}$ dependence in parallel field for the $2 \mathrm{G} 248$ reduces mostly linearly with field, which indicates that effective pinning is maintained for the parallel direction over the entire field range; for the perpendicular direction pinning is most effective at low fields but then reduces at high fields.

Figure 10 shows the ratio of $I_{c}$, normalized to $I_{c}(77 \mathrm{~K}, 0 \mathrm{~T})$, in parallel field to that in transverse field as a function of applied magnetic field at the various temperatures. Contrary to the $1 \mathrm{G}$ conductor, in this case there is no observable temperature dependence. The ratio tends to saturate at high fields, at around 7.

Figures 11 and 12 show the $I_{c}$ normalized to $I_{c}(77 \mathrm{~K}, 0 \mathrm{~T})$ as a function of field and field angle at $4.2 \mathrm{~K}$ and $33 \mathrm{~K}$. Also for the $2 \mathrm{G}$, most of the $\mathrm{I}_{\mathrm{c}}$ reduction occurs between 90 and 45 degree, with a possible indication of a more gradual reduction with angle at $4.2 \mathrm{~K}$, but more data would be needed to confirm this.

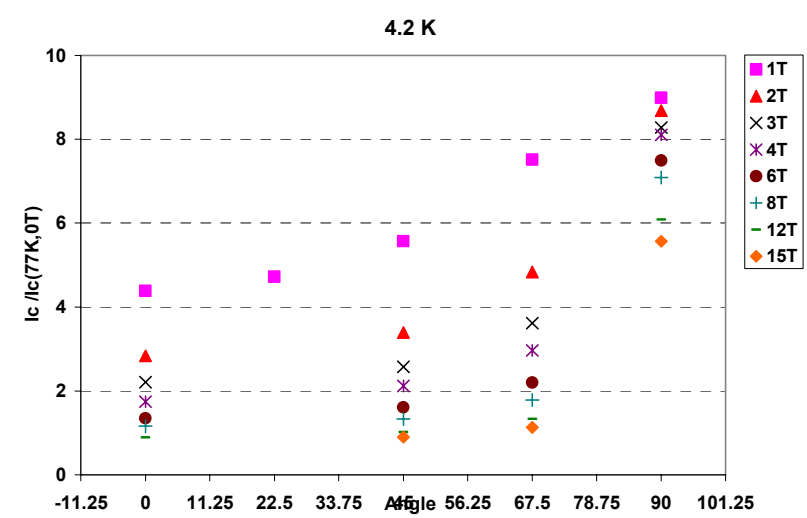

FIGURE 11. Normalized $\mathrm{I}_{\mathrm{c}}(4.2 \mathrm{~K})$ of the $2 \mathrm{G}$ coated conductor versus $\mathrm{B}$ and $\Theta$.

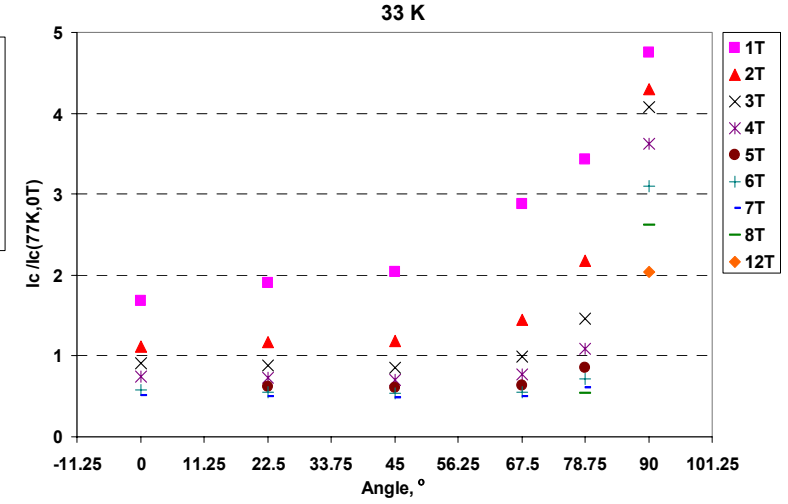

FIGURE 12. Normalized $\mathrm{I}_{\mathrm{c}}(33 \mathrm{~K})$ of the $2 \mathrm{G}$ coated conductor versus $\mathrm{B}$ and $\Theta$. 


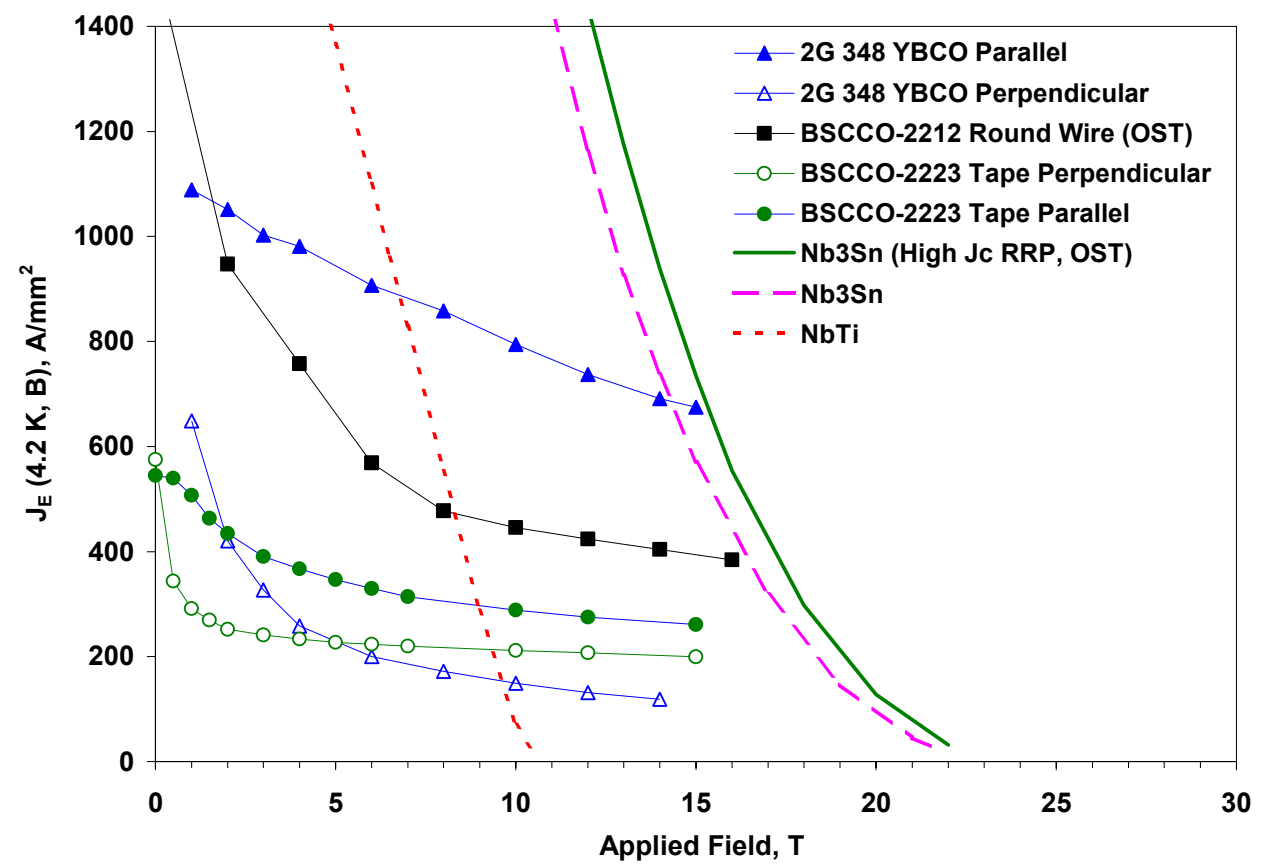

FIGURE 13. $\mathrm{J}_{\mathrm{E}}(\mathrm{B})$ at $4.2 \mathrm{~K}$ for 348 superconductors, Bi-2223 wire, round Bi-2212 wire (OST), and high current density $\mathrm{Nb}_{3} \mathrm{Sn}$ wire.

\section{Comparison with Low Temperature Superconductors}

Figure 13 shows the engineering critical current $\mathrm{J}_{\mathrm{E}}$ at $4.2 \mathrm{~K}$ and magnetic fields up to 15 $\mathrm{T}$, for $2 \mathrm{G} 348$ and $\mathrm{Bi}-2223$ superconductors, and round $\mathrm{Bi}-2212(\mathrm{OST}), \mathrm{Nb}_{3} \mathrm{Sn}$ and $\mathrm{NbTi}$ wires. For the calculation of $\mathrm{J}_{\mathrm{E}}$ of the $2 \mathrm{G} 348$ conductor the entire cross section was used. Below $15 \mathrm{~T}$, the $\mathrm{J}_{\mathrm{E}}$ of the RPP $\mathrm{Nb}_{3} \mathrm{Sn}$ wire exceeds that of all HTS at $4.2 \mathrm{~K}$. Above $17 \mathrm{~T}$ the Bi-2212 conductor shows an excellent overall performance. The 348 superconductors show a much higher current density in parallel fields, indicating excellent potential for high current density insert magnets for very high fields. For complete solenoids in which end sections operate with high perpendicular field components the $B_{\text {perp }}$ performance is currently too low and needs further pinning enhancement for this field direction. The Bi-2223 conductor shows a lower engineering critical current density than either Bi-2212 or 348, but combines high strength, react and wind capability, and low angular field dependence of $\mathrm{J}_{\mathrm{c}}$.

\section{CONCLUSIONS}

A sample holder was designed to perform $I_{c}$ measurements of HTS tapes under externally applied magnetic fields, with orientations varying from zero to 90 degree with respect to the caxis. This was performed from $1.8 \mathrm{~K}$ to $33 \mathrm{~K}$ up to $15 \mathrm{~T}$, while providing up to $1200 \mathrm{~A}$ of current. The data are consistent with similar measurements performed by AMSC in a perpendicular field at $4.2 \mathrm{~K}$ [2]. Measurements at $4.2 \mathrm{~K}$ and at fields between 15 and $25 \mathrm{~T}$ are planned. The engineering critical current for the new double layer hybrid $2 \mathrm{G}$ HTS superconductor competes well with existing conductors for parallel field orientations, and as such, would be an excellent candidate for high field insert magnets operating above 16-18 $\mathrm{T}$. 
Further pinning development would be needed to ensure proper operation in solenoids with strong perpendicular field components in the end sections.

With the present 348 superconductors, another important specification that needs to be addressed next in the design of high field solenoids is the very large strain these magnets are subject to. This would complement axial strain dependence measurements on earlier conductors $[11,12]$.

\section{ACKNOWLEDGMENTS}

We thank the special people of our Superconductor R\&D group at FNAL, Al Rusy and Tom VanRaes, whose skills and commitment were essential for this work.

\section{REFERENCES}

1. Goyal, D.P. Norton, J.D. Budai, M. Paranthaman, E.D. Specht, D.M. Kroeger, D.K. Christen, Q. He, B. Saffian, F.A. List, D.F. Lee, P. M. Martin, C.E. Klabunde, E. Hardtfield, and V.K. Sikka, Appl. Phys. Lett. 69, 1975 (1996).

2. C.L.H. Thieme, S. Annavarapu, W. Zhang, V. Prunier, L. Fritzemeier, Q. Li, U. Schoop, M.W. Rupich, M. Gopal, S. Foltyn and T. Holesinger.," Non-magnetic Substrates for Low Cost YBCO Coated Conductors", IEEE Trans. Appl. Superc. 11, p. 3329 (2001).

3. X. Li ${ }^{\mathrm{a}}$, M.W. Rupich, T. Kodenkandath, Y. Huang, W. Zhang, E .Siegal, D. T. Verebelyi, U. Schoop, N. Nguyen, C. Thieme, Z. Chen, D.M. Feldman, D. C. Larbalestier, T.G. Holesinger, L. Civale, X. Jia, V. Maroni, and M.V. Rane, "High Critical Current YBCO Films Prepared by an MOD Process on RABiTS Templates", to appear in IEEE Trans. Appl. Superc. 17 (2007).

4. M. W. Rupich, U. Schoop, D. T. Verebelyi, C. Thieme, W. Zhang, X. Li, T. Kodenkandath, N. Nguyen, E. Siegal, D. Buczek, J. Lynch, M. Jowett, E.Thompson, J-S. Wang, J. Scudiere, A. P. Malozemoff, Q. Li, S. Annavarapu, S. Cui, L. Fritzemeier, B. Aldrich, C. Craven, F. Niu, A. Goyal, and M. Paranthaman, "YBCO Coated Conductors, IEEE Trans. Appl. Superc. 13, p. 2458 (2003).

5. M. W. Rupich, U. Schoop, C. Thieme, D. T. Verebelyi, W. Zhang, X. Li, T. Kodenkandath, N. Nguyen, E. Siegal, L. Civale, T. Holesinger, A. Goyal, and M. Paranthaman," Second Generation HTS Wire Based on RABiTS $^{\text {TM }}$ Substrates and MOD YBCO”, IEEE Trans. Appl. Superc. 15, p. 2458 (2005).

6. M.W. Rupich, U. Schoop, D.T. Verebelyi, C.L.H. Thieme, D. Buczek, X. Li, W. Zhang, T. Kodenkandath, Y. Huang, E. Siegal, W. Carter, N. Nguyen, J. Schreiber, M. Prasova, J. Lynch, D. Tucker, R. Harnois, C. King, D. Aized, "The Development of Second Generation HTS Wire at American Superconductor", to appear in IEEE Trans. Appl. Superc. 17 (2007).

7. W. Zhang, Y. Huang, X. Li, T. Kodenkandath, M.W. Rupich, U. Schoop, D.T.Verebelyi, C.L.H. Thieme, E. Siegal, T.G. Holesinger, B. Maiorov, L.Civale, D.J. Miller, V.A. Maroni, J. Li, P.M. Martin, E.D. Specht, A. Goyal and M.P. Paranthaman, "Control of Flux Pinning in MOD YBCO Coated Conductor," to appear in IEEE Trans. Appl. Superc. 17 (2007).

8. B. Xu, J.H. Su and J. Schwartz, "Dependence of transport critical current of magnetic field processed $\mathrm{Bi}_{2} \mathrm{Sr}_{2} \mathrm{CaCu}_{2} \mathrm{O}_{\mathrm{X}} / \mathrm{AgMg}$ tapes on the background magnetic field and magnetic field direction," Superconductor Science and Technology 18 503-507 (2005).

9. T. Holesinger and L. Civale," Multi-scale Characterization of Structure and Properties of Coated Conductors", DOE Superconductivity for Electric Systems 2006 Annual Peer Review, August 2006, Washington, D.C.

10. E. Barzi et al., "High Temperature Superconductors for High Field Superconducting Magnets", Advances in Cryogenic Engineering, V. 52, p. 416, 2006.

11. J. Ekin, N. Cheggour, DOE Superconductivity for Electric Systems 2004 Annual Peer Review, July 2004, Washington, D.C.

12. D Uglietti, B Seeber, V Abächerli, W L Carter and R Flükiger, "Critical currents versus applied strain for industrial Y-123 coated conductors at various temperatures and magnetic fields up to 19 T", Supercond. Sci. Technol. 19 No 8 (August 2006) 869-872. 